\title{
Alcoholic beverage intake throughout the week and contribution to dietary energy intake in Australian adults
}

\author{
Brooke S Wymond ${ }^{1}$, Kacie M Dickinson ${ }^{1}$ and Malcolm D Riley ${ }^{2, *}$ \\ ${ }^{1}$ Nutrition and Dietetics, School of Health Science, Flinders University, Adelaide, SA, Australia: ${ }^{2}$ Commonwealth \\ Scientific and Industrial Research Organisation, Food and Nutrition Flagship, CSIRO, PO Box 10041, Adelaide BC, \\ SA 5000, Australia
}

Submitted 9 July 2015: Final revision received 24 February 2016: Accepted 2 March 2016: First published online 1 April 2016

\begin{abstract}
Objective: To assess alcoholic beverage intake among Australian adults and its contribution to dietary energy intake.

Design: Secondary analysis of a national dietary survey using $24 \mathrm{~h}$ dietary recall. Setting: Australian National Nutrition and Physical Activity Survey (NNPAS) conducted from May 2011 to June 2012.

Subjects: Adults ( $n$ 9341) aged 19 years and over.

Results: On the day preceding the survey, $32 \cdot 8 \%$ of Australian adults consumed one or more alcoholic drinks. The median contribution to total energy intake for consumers did not differ significantly between males and females $(13.7 \%$ and $12.9 \%$, respectively; $P=0 \cdot 10)$. The prevalence of consumption of alcoholic drinks on Friday, Saturday and Sunday was 38.8 (95\% CI 37.1, 40.5)\%, higher than the other days (28.6 (95\% CI 27.5, 29.8)\%). Consumers had a median daily intake of 4.0 standard drinks on the weekend compared with 3.0 standard drinks during the week $(P<0 \cdot 001)$. Beer was the most commonly consumed alcoholic beverage for men and white wine for women. The highest prevalence of alcoholic beverage intake occurred in the highest quintile of adjusted household income (42.7 (95\% CI 40.4, 45.0)\%) and the 'overweight' BMI category (40.3 (95\% CI 38.5, 42.0)\%). Alcoholic beverage intake among consumers was significantly different by household income quintile (median 3.84 (highest) $v .3 .05$ standard drinks (lowest); $P<0.05$ ) and by waist circumference category (median 4.09 standard drinks (highest)).

Conclusions: Alcoholic drinks contribute substantially to the dietary energy intake of Australian adults. The type and pattern of consumption of alcoholic beverage intake should be considered in the development of strategies to improve dietary intake.
\end{abstract}

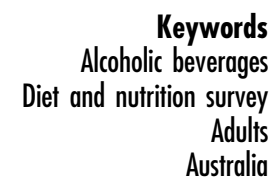

Alcohol is an intrinsic part of Australian culture and plays a central role in the social life of most people ${ }^{(1)}$. In 20112012, 82.4\% of Australians aged 18 years and over had consumed alcohol in the last year and $19.5 \%$ of these people reported that they consumed more than two standard drinks per day on average ${ }^{(2)}$, exceeding the National Health and Medical Research Council's lifetime risk guidelines ${ }^{(3)}$. Consumption of alcoholic beverages is seen as acceptable in almost all social situations in Australia, despite the substantial negative social, health and economic consequences it can cause ${ }^{(1,4)}$.

Some level of alcohol consumption has been causally linked to more than sixty medical conditions including cancer $^{(5)}$. An estimated 3430 deaths per year and 85435 disability-adjusted life years are lost in Australia each year due to alcohol consumption ${ }^{(5)}$. Conversely, moderate alcohol consumption has been found to have protective effects against $\mathrm{CVD}^{(6)}$; however, these positive effects disappear completely in the presence of heavy episodic drinking $^{(7)}$. A dose-response relationship is apparent for most diseases causally impacted by alcohol, including cancer $^{(4)}$.

In addition to the direct health risks associated with alcohol, alcoholic beverages may also result in the addition of significant amounts of energy to people's diet. Alcoholic beverages can result in increased dietary energy consumption by providing metabolic energy and also by appetite stimulation $^{(8)}$ and limiting satiety development ${ }^{(9)}$. Alcoholic beverages are generally nutrient poor and in some contexts may be associated with consumption of excess kilojoules beyond alcohol, such as when consumed mixed with sugary drinks ${ }^{(10)}$ or accompanied 
by high-fat/high-energy snack foods ${ }^{(11)}$. The consumption of alcoholic beverages may therefore be an important contributor to overweight and obesity.

The prevalence of overweight and obesity is a major health problem in developed countries, with about 3.4 million adults dying each year as a result of being overweight or obese $^{(12)}$. In Australia, $62.8 \%$ of Australian adults were overweight or obese in 2011-2012 $2^{(13)}$. Excess weight, especially obesity, is an important risk factor for CVD, type 2 diabetes and some cancers ${ }^{(14)}$.

Long-term weight gain can result from energy intake exceeding energy expenditure every day or only on some days of the week such as weekend days ${ }^{(15)}$. Data from the 1995 Australian National Nutrition Survey ${ }^{(16)}$, as well as studies in other developed countries ${ }^{(17-19)}$, have shown higher alcoholic beverage consumption on weekends compared with weekdays. People tend to consume more alcohol on weekends than weekdays as this is when many special events and leisure activities are scheduled ${ }^{(20)}$.

The consumption patterns of alcoholic beverages in Australia have not been examined at the population level since the last National Nutrition Survey in $1995^{(16)}$. An analysis of alcoholic beverage consumption in Australia is therefore warranted to provide insight into the groups who are the highest consumers, the types of alcoholic beverages consumed and the days on which they are consumed.

The present paper describes alcoholic beverage consumption of Australian adults aged 19 years and over in 2011-2012, and includes the prevalence of alcoholic beverage consumption on the day preceding the survey, the type and amount of alcoholic beverages consumed and the energy contribution to total energy intake, reported by sex, age group, household income and measures of adiposity.

\section{Methods}

\section{Study design}

The analysis utilises data collected by the Australian Bureau of Statistics in the 2011-2012 Australian National Nutrition and Physical Activity Survey (NNPAS), a component of the Australian Health Survey ${ }^{(21)}$. The NNPAS is a cross-sectional survey that collected demographic, dietary, anthropometric and physical activity data from a nationally representative sample of people aged 2 years and over between 29 May 2011 and 9 June $2012^{(22)}$.

The sample was selected from across Australia using a stratified, multistage, area sample of private dwellings ${ }^{(23)}$. The full details of the sampling methodology can be found elsewhere ${ }^{(23)}$. The NNPAS was conducted in 9500 private dwellings on 12153 persons (response prevalence of $77 \%)$ throughout urban and rural areas of Australia. The sampling frame represented about $97 \%$ of people living in Australia $^{(22)}$.
The current analysis includes adults only, due to the low level and atypical alcohol intake among children. The legal age for drinking alcohol in a licensed venue or a public place is 18 years in Australia ${ }^{(24)}$. Age category 19 years and over was chosen to represent adults, rather than age 18 years, to be consistent with the data available from the Australian Bureau of Statistics' 1995 National Nutrition Survey as well as the Australian Dietary Guidelines (2013) that both define those aged 19 years and above as adults ${ }^{(16,25)}$.

\section{Dietary assessment}

Trained interviewers from the Australian Bureau of Statistics collected dietary information from participants on two separate occasions. The first survey was conducted via a computer-assisted personal interview and the second survey was conducted a minimum of $8 \mathrm{~d}$ later by a computer-assisted telephone interview. Both surveys were conducted using the Automated Multiple Pass Method which has been adapted from the US Department of Agriculture $^{(23)}$. Only information from the computerassisted personal interview is used in the current report. This was to avoid potential issues of combining dietary intake data collected using slightly different methods, as well as the fact that data for the second day of intake were collected for only $64 \%$ of people surveyed on day 1 . Food intake data were converted to nutrient intakes using AUSNUT 2011-2013, a database of food composition developed specifically for the 2011-2012 NNPAS ${ }^{(26)}$.

\section{Alcoholic beverages classification}

The food records for the NNPAS identified alcoholic beverage types consumed. Where an alcoholic beverage was consumed as part of a food recipe (e.g. brandy in brandy custard, white wine in risotto) the beverage was manually identified and excluded from this analysis. Soft drinks or fruit juices that were consumed at the same time as an alcoholic spirit were considered to have been mixed with the alcoholic beverage, and the weight and energy content of these components were totalled. The alcoholic beverages were categorised for analysis as follows: Beer (full strength or $>3.5 \%$ alcohol content); Low-Alcohol Beer (1.15-3.5\% alcohol) and Low-Alcohol Wine; Red Wine (including sparking varieties and rosé style); White Wine (including sparking varieties); Fortified Wine (port and sherry); Spirits (consumed alone or with ice/water); Cider and Perry (referred to as 'Cider'); Liqueurs, Cocktails and Other Mixed Drinks ('Mixed Drinks or Cocktails'); and Pre-Mixed Cola or Energy-Based Drinks and Other Pre-Mixed Drinks ('Premixes').

The alcoholic beverage amount consumed was converted from weight to number of standard drinks using as a conversion factor that one standard drink contains $10 \mathrm{~g}$ of alcohol $^{(27)}$.

BMI was calculated using measured weight and height and the cut-off points for underweight, normal weight, overweight and obese were those described by the $\mathrm{WHO}^{(28)}$. 
Measured waist circumference categories were as recommended by the National Health and Medical Research Council (increased risk at $>80 \mathrm{~cm}$ for women and $>94 \mathrm{~cm}$ for men; high risk at $>88 \mathrm{~cm}$ for women and $>102 \mathrm{~cm}$ for men). The socio-economic status of participants was represented using the gross equivalised household income deciles provided with the data ${ }^{(23)}$. The equivalised household income is the reported household income adjusted to take account of the size of the household and its composition. For convenience, in the current analysis the deciles were categorised as quintiles.

\section{Statistical analysis}

The percentage of adults consuming alcoholic beverages on the day preceding the survey was reported, and the median intake and percentage of total energy from alcoholic beverages were reported for adults who had consumed an alcoholic beverage only. Estimates were stratified by age group, sex, day of the week, waist circumference and BMI categories, and equivalised household income quintiles. Days of the week were further categorised as weekdays (Monday, Tuesday, Wednesday, Thursday) and weekends (Friday, Saturday and Sunday). Consumer-only data were used for alcoholic beverage intake and percentage of energy from alcoholic beverages because of the relevance of expressing daily intake measures for people who displayed consumption behaviour. Statistical analyses were performed using the statistical software package IBM SPSS Statistics Version 22 (2013).

All estimates were population weighted to take account of non-response and the non-proportionate nature of the sampling method. Each participant was assigned a population weighting factor which weighted for age, sex and region based on the 2011 Census of Population and Housing ${ }^{(23)}$. The population weights were rescaled to the size of the sample for statistical analysis. Where appropriate, a further weighting was applied to account for the non-uniform representation of day of the week in the dietary intake data.

Non-parametric statistics were used to determine the significance of differences in distribution estimates by category. For continuous variables such as intake of alcoholic beverages and percentage of total energy contribution, comparison across two groups (such as sex) was undertaken using a Mann-Whitney $U$ test. For comparison across more than two categories (such as age group, household income quintile and BMI category), a Kruskal-Wallis test was performed followed by pairwise comparisons regardless of whether the variable was continuous or dichotomous (e.g. for prevalence comparisons). Results were considered to be statistically significant where $P<0 \cdot 05$.

\section{Results}

Basic characteristics of survey participants are listed in Table 1.
Table 1 Basic characteristics of surveyed Australian adults aged 19 years and over ( $n$ 9341, unweighted)

\begin{tabular}{|c|c|c|c|c|c|}
\hline \multirow[b]{2}{*}{ Characteristic } & \multicolumn{2}{|c|}{ Men } & \multicolumn{2}{|c|}{ Women } & \multirow[b]{2}{*}{$P$ value } \\
\hline & $n$ & $\%$ & $n$ & $\%$ & \\
\hline & 4282 & 46 & 5059 & 54 & \\
\hline \multicolumn{6}{|l|}{ Age group (years) } \\
\hline $19-24$ & 326 & 8 & 360 & 7 & \\
\hline $25-44$ & 1593 & 37 & 1867 & 37 & \\
\hline $45-64$ & 1453 & 34 & 1639 & 32 & \\
\hline $65-79$ & 728 & 17 & 912 & 18 & \\
\hline$\geq 80$ & 182 & 4 & 281 & 6 & \\
\hline \multicolumn{6}{|l|}{ BMI category $\dagger$} \\
\hline Underweight & 35 & 1 & 81 & 2 & \\
\hline Healthy weight & 1031 & 28 & 1647 & 40 & \\
\hline Overweight & 1648 & 44 & 1235 & 30 & \\
\hline Obese & 1028 & 27 & 1168 & 28 & \\
\hline \multicolumn{6}{|c|}{ Waist circumference category $\ddagger$} \\
\hline Not at risk & 1423 & 38 & 1225 & 30 & \\
\hline Increased risk & 898 & 24 & 890 & 22 & \\
\hline High risk & 1426 & 38 & 1988 & 48 & \\
\hline
\end{tabular}

${ }^{*}$ For difference in distribution across categories between men and women. †Weight and height were measured for 7873 participants. BMI categories are: underweight, $<18.50 \mathrm{~kg} / \mathrm{m}^{2}$; healthy weight, 18.50 to $24.99 \mathrm{~kg} / \mathrm{m}^{2}$; overweight, 25.00 to $29.99 \mathrm{~kg} / \mathrm{m}^{2}$; obese, $\geq 30.00 \mathrm{~kg} / \mathrm{m}^{2}$.

$\ddagger$ Waist circumference was measured for 7850 participants. Increased risk category is $>80 \mathrm{~cm}$ for women and $>94 \mathrm{~cm}$ for men; high risk category is $>88 \mathrm{~cm}$ for women and $>102 \mathrm{~cm}$ for men.

Consumption of alcoholic beverages by age and sex Overall, alcoholic beverages were consumed on the day preceding the survey by $32 \cdot 8$ (95\% CI $31 \cdot 8,33 \cdot 7) \%$ of adults. For men and women, the lowest prevalence of alcoholic beverage consumption occurred in the youngest age group (19-24 year olds; Table 2). For every age group the prevalence of alcoholic drink consumption was significantly greater for men than it was for women $(P<0 \cdot 05)$. The prevalence of women consuming alcohol across all age groups was $25 \cdot 0$ (95\% CI 23.8, 26.3)\% compared with men at $40.4(95 \%$ CI 39.0, 41.8) \% ( $P<0 \cdot 001)$.

Men consumers had a higher intake of alcoholic beverages than women overall (median: $3.84 v .2 .86$ standard drinks; $P<0 \cdot 001$ ). However, the energy contribution from alcoholic beverages did not differ between men and women overall (median: 13.7 v. $12.9 \%$, respectively; $P=0 \cdot 10$ ), although it was significantly higher for men compared with women in the 19-24 year age group (Table 2).

The median percentage of energy from alcoholic beverages for consumers was greater than $10 \%$ of total energy for all age groups except women aged 19-24 years and women and men aged over 80 years.

There was no statistically significant difference between regions (major cities, inner regional, other) for prevalence of consumption or for amount consumed.

\section{Consumption patterns by day of the week}

The prevalence of consuming alcoholic beverages was significantly lower on Monday to Thursday (28.6 (95\% CI $27 \cdot 4,29 \cdot 8) \%$ compared with Friday to Sunday 
Table 2 Percentage who consumed an alcoholic beverage, their median intake and median percentage of total energy contribution, by sex and age group, for adults aged 19 years and over using population-weighted, $1 \mathrm{~d}$ intake data from the Australian National Nutrition and Physical Activity Survey, May 2011-June 2012

\begin{tabular}{|c|c|c|c|c|c|c|c|c|}
\hline \multirow[b]{3}{*}{ Sex/age group (years) } & & & \multicolumn{6}{|c|}{ Consumers only } \\
\hline & \multicolumn{2}{|c|}{ Population prevalence } & \multicolumn{3}{|c|}{ 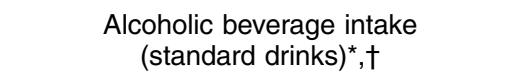 } & \multicolumn{3}{|c|}{$\begin{array}{l}\text { Percentage of total energy from } \\
\text { alcoholic beverages }(\%)^{\star}, \ddagger\end{array}$} \\
\hline & $\%$ & $95 \% \mathrm{Cl}$ & Median & 10th-90th percentile & $P \S$ & Median & 10th-90th percentile & $P \S$ \\
\hline \multicolumn{9}{|l|}{ Men } \\
\hline $19-24$ & $20 \cdot 8$ & $17 \cdot 4,24 \cdot 0$ & $4 \cdot 0^{\mathrm{a}, \mathrm{b}}$ & $1 \cdot 3-12 \cdot 7$ & $<0.001$ & $16 \cdot 5^{\mathrm{a}}$ & $3 \cdot 8-45 \cdot 7$ & 0.003 \\
\hline $25-44$ & $41 \cdot 0$ & $38 \cdot 8,43 \cdot 2$ & $4 \cdot 1^{\mathrm{a}}$ & $1 \cdot 2-11 \cdot 1$ & 0.22 & $13 \cdot 9^{a}$ & $5 \cdot 0-39 \cdot 2$ & 0.77 \\
\hline $45-64$ & 44.0 & $41 \cdot 6,46 \cdot 3$ & $4 \cdot 1^{\mathrm{a}}$ & $1.4-10.2$ & $<0.001$ & $14 \cdot 3^{\mathrm{a}}$ & $5 \cdot 5-33 \cdot 5$ & 0.09 \\
\hline $65-79$ & 49.7 & $45 \cdot 6,53 \cdot 8$ & $3 \cdot 1^{\mathrm{b}, \mathrm{c}}$ & $1 \cdot 1-7 \cdot 9$ & 0.11 & $13 \cdot 5^{a, b}$ & $5 \cdot 7-28 \cdot 6$ & 0.27 \\
\hline$\geq 80$ & $37 \cdot 0$ & $28 \cdot 8,45 \cdot 2$ & $2 \cdot 5^{\mathrm{C}}$ & $0.8-6.5$ & 0.61 & $9 \cdot 9^{\mathrm{b}}$ & $2 \cdot 8-32 \cdot 3$ & 0.98 \\
\hline \multicolumn{9}{|l|}{ Women } \\
\hline $19-24$ & $15 \cdot 4$ & $12 \cdot 4,18 \cdot 3$ & $2 \cdot 3^{a, b}$ & $0.2-10.4$ & & $9 \cdot 6^{\mathrm{a}}$ & $1 \cdot 4-52 \cdot 2$ & \\
\hline $25-44$ & $22 \cdot 7$ & $20 \cdot 8,24 \cdot 7$ & $3 \cdot 1^{\mathrm{c}}$ & $1.3-10.0$ & & $13 \cdot 8^{b}$ & $4 \cdot 6-36 \cdot 2$ & \\
\hline $45-64$ & 31.5 & $29 \cdot 1,33 \cdot 8$ & $3 \cdot 0^{c, d}$ & $0.9-8.2$ & & $13 \cdot 8^{a, b}$ & $3.9-33.2$ & \\
\hline $65-79$ & 24.8 & $21 \cdot 4,28 \cdot 2$ & $2 \cdot 7^{\mathrm{b}, \mathrm{d}}$ & $1.0-7.0$ & & $12 \cdot 9^{\mathrm{a}, \mathrm{b}}$ & $4.9-31 \cdot 8$ & \\
\hline$\geq 80$ & $25 \cdot 2$ & $19 \cdot 1,31 \cdot 3$ & $2 \cdot 3^{\mathrm{b}, \mathrm{c}}$ & $0.9-12.8$ & & $8 \cdot 7^{\mathrm{a}, \mathrm{b}}$ & $4 \cdot 1-35 \cdot 3$ & \\
\hline \multicolumn{9}{|l|}{ Total } \\
\hline $19-24$ & $18 \cdot 1$ & $15 \cdot 9,20 \cdot 3$ & $2 \cdot 8^{\mathrm{a}, \mathrm{b}}$ & $0.9-12.3$ & & $12 \cdot 4^{\mathrm{a}, \mathrm{b}}$ & $3 \cdot 3-45 \cdot 7$ & \\
\hline $25-44$ & $32 \cdot 2$ & $30 \cdot 6,33 \cdot 7$ & $3.8^{\mathrm{a}}$ & $1 \cdot 2-10 \cdot 9$ & & $13 \cdot 8^{\mathrm{a}}$ & $4 \cdot 8-39 \cdot 2$ & \\
\hline $45-64$ & 37.8 & $36.0,39.5$ & $3 \cdot 4^{\mathrm{a}}$ & $1 \cdot 3-9 \cdot 3$ & & $14.0^{\mathrm{a}}$ & $5 \cdot 0-33 \cdot 5$ & \\
\hline $65-79$ & $36 \cdot 6$ & $33.9,39.3$ & $2 \cdot 8^{\mathrm{b}}$ & $1.0-7.6$ & & $13 \cdot 4^{a, b}$ & $5 \cdot 5-28.9$ & \\
\hline$\geq 80$ & 30.0 & $25 \cdot 1,35 \cdot 0$ & $2 \cdot 3^{b}$ & $0.9-7.7$ & & $9 \cdot 3^{\mathrm{b}}$ & $3 \cdot 5-33 \cdot 4$ & \\
\hline
\end{tabular}

a,b,c,d For each sex, median values within a column with unlike superscript letters were significantly different $(P<0.05)$.

*The independent-samples Kruskal-Wallis test, followed by pairwise comparisons, was used to test for differences in alcoholic beverage intake and percentage energy from alcoholic beverages between age groups.

†One standard drink contains $10 \mathrm{~g}$ of alcohol ${ }^{(27)}$.

$\ddagger$ Percentage of total energy from alcoholic beverages includes energy from soft drinks mixed with alcoholic beverages where applicable.

$\S$ The Mann-Whitney $U$ test was used to test for differences in alcoholic beverage intake and percentage energy from alcoholic beverages between men and women.

Table 3 Percentage who consumed an alcoholic beverage, their median intake and median percentage of total energy contribution, by day of the week, for adults aged 19 years and over using population-weighted, $1 \mathrm{~d}$ intake data from the Australian National Nutrition and Physical Activity Survey, May 2011-June 2012

\begin{tabular}{|c|c|c|c|c|c|c|}
\hline \multirow[b]{3}{*}{ Day of week } & \multirow{2}{*}{\multicolumn{2}{|c|}{ Population prevalence* }} & \multicolumn{4}{|c|}{ Consumers only } \\
\hline & & & \multicolumn{2}{|c|}{$\begin{array}{l}\text { Alcoholic beverage intake } \\
\text { (standard drinks) }{ }^{\star}, \dagger\end{array}$} & \multicolumn{2}{|c|}{$\begin{array}{l}\text { Percentage of total energy from } \\
\text { alcoholic beverages }(\%)^{\star}, \ddagger\end{array}$} \\
\hline & $\%$ & $95 \% \mathrm{Cl}$ & Median & 10th-90th percentile & Median & 10th-90th percentile \\
\hline Monday & $27 \cdot 7^{\mathrm{a}}$ & $25 \cdot 3,30 \cdot 1$ & $2 \cdot 94^{\mathrm{a}}$ & $1.20-8.17$ & $11 \cdot 6^{\mathrm{a}}$ & $4 \cdot 1-29 \cdot 0$ \\
\hline Tuesday & $28 \cdot 6^{a}$ & $26 \cdot 2,31 \cdot 0$ & $2 \cdot 86^{a, b}$ & $1.13-8.75$ & $12 \cdot 3^{a, b}$ & $4 \cdot 4-32 \cdot 1$ \\
\hline Wednesday & $30.7^{\mathrm{a}, \mathrm{c}}$ & $28 \cdot 2,33 \cdot 3$ & $3 \cdot 27^{a, b}$ & $1.04-8.31$ & $13 \cdot 9^{a, b}$ & $4 \cdot 9-30 \cdot 1$ \\
\hline Thursday & $27 \cdot 6^{\mathrm{a}}$ & $25 \cdot 2,30 \cdot 0$ & $2 \cdot 94^{\mathrm{a}, \mathrm{b}}$ & $1 \cdot 16-8.61$ & $12 \cdot 7^{\mathrm{a}, \mathrm{b}}$ & $4 \cdot 6-31 \cdot 3$ \\
\hline Friday & $39.8^{\mathrm{b}}$ & $37 \cdot 2,42 \cdot 4$ & $3 \cdot 82^{b, c}$ & $1.20-9.82$ & $12 \cdot 8^{\mathrm{b}}$ & $4 \cdot 8-38 \cdot 0$ \\
\hline Saturday & $35 \cdot 7^{\mathrm{b}, \mathrm{c}}$ & $33 \cdot 1,38.2$ & $4 \cdot 23^{c}$ & $1.06-12.91$ & $17 \cdot 3^{\mathrm{b}}$ & $5 \cdot 3-43 \cdot 7$ \\
\hline Sunday & $38.7^{\mathrm{b}}$ & $36 \cdot 2,41 \cdot 3$ & $3.40^{\mathrm{b}, \mathrm{c}}$ & $1.27-10 \cdot 25$ & $14 \cdot 0^{a, b}$ & $5 \cdot 3-36 \cdot 6$ \\
\hline
\end{tabular}

a,b,c Values within a column with unlike superscript letters were significantly different $(P<0.05)$.

*The independent-samples Kruskal-Wallis test, followed by pairwise comparisons, was used to test for differences in prevalence, alcoholic beverage intake and percentage energy from alcoholic beverages between days of the week.

†One standard drink contains $10 \mathrm{~g}$ of alcohol ${ }^{(27)}$.

†Percentage of total energy from alcoholic beverages includes energy from soft drinks mixed with alcoholic beverages where applicable.

(38.1 (95\% CI 36.6, 39.6)\%). For consumers, the median daily amount of alcoholic beverages consumed was lower on Monday to Thursday compared with Friday to Sunday (median: 2.96 v. 4.04 standard drinks; $P<0.001$ ) and the percentage contribution of alcoholic beverages to energy intake was also lower (median: $12.6 \%$ on Monday to Thursday $v \cdot 14.3 \%$ on Friday to Sunday; $P=0 \cdot 001$ ). Adults consumed significantly less alcoholic beverages measured in standard drinks on Monday, Tuesday, Wednesday and Thursday compared with Saturday (Table 3). Although the median percentage of energy from alcoholic beverages was high on Saturday (17.3\%), the distribution of percentage of energy from alcoholic beverages was not significantly different from any other day except for Monday. When weekend is defined as Friday, Saturday and Sunday, men had a prevalence of consumption of $35.2(95 \%$ CI $33 \cdot 3$, 
$37 \cdot 0$ ) \% during the weekdays and $46 \cdot 8$ (95\% CI 44.6, 48.9)\% on the weekend. For women, the prevalence was $22.5(95 \%$ CI 20.9, 24.0) \% during weekdays and 28.6 (95\% CI 26.6, 30.6) \% on the weekend.

\section{Consumption patterns by type of alcobolic beverages consumed}

Table 4 describes the intake of different types of alcoholic beverage for men and women. Beer was consumed by the highest percentage of adults on the day preceding the survey, followed by red wine, white wine and then low-alcohol beverages. For adult men, beer was the alcoholic beverage with the highest prevalence of intake on the day preceding the survey (19.4\%); however, for women white wine showed the highest prevalence (10.1\%). The median intake of beer for adult men was $3 \cdot 1$ standard drinks, while the median intake of white wine for women was 3.3 standard drinks.

When the beverage was reported to be consumed, men had significantly more beer, red wine, low-alcohol drinks, and mixed drinks or cocktails than women consumers for the reported day $(P<0.05$; Table 4$)$. However, the percentage of total energy from the specific alcoholic beverages was significantly greater for men consumers only for beer and low-alcohol drinks compared with women consumers $(P<0.05$; Table 4$)$. Women consumers of white wine had a significantly higher percentage of their total energy from white wine than men consumers of white wine $(P<0.05)$, with a similar pattern for consumers of spirits (Table 4).
Consumption of alcobolic beverages at the weekend

When weekend is defined as Friday, Saturday and Sunday, the mean amount of alcoholic beverage consumed for men was 1.58 standard drinks on weekdays and 2.45 standard drinks on the weekend $(P<0 \cdot 001)$. For women, the mean amount consumed was 0.84 standards drinks on weekdays and 1.36 standard drinks on the weekend $(P<0.001)$. The percentage of total energy provided by alcoholic beverages for men was $5.7 \%$ on weekdays and $8.7 \%$ on the weekend $(P<0.001)$. For women, the percentage of total energy provided was $3.4 \%$ on weekdays and $5.4 \%$ on the weekend $(P<0.001)$.

For consumers only, the median amount of alcoholic beverage consumed by men consumers was 3.27 standard drinks on weekdays and 4.15 standard drinks on the weekend $(P<0.001 ;$ Fig. 1$)$. For women, the median amount consumed by consumers was 2.73 standard drinks on weekdays and 3.11 standard drinks on the weekend $(P=0 \cdot 001)$. The median percentage of total energy provided by alcoholic beverages for men consumers was $13.1 \%$ on weekdays and $14.3 \%$ on the weekend $(P=0.05$; Fig. 2). For women consumers, the median percentage of total energy provided was $11.8 \%$ on weekdays and $14.5 \%$ $(P=0.05)$ on the weekend.

\section{Association with bousebold income}

The highest prevalence of consumption of alcoholic beverages occurred in the top quintile of equivalised

Table 4 Percentage who consumed an alcoholic beverage, their median intake and median percentage of total energy contribution, by type of alcoholic beverage consumed and sex, for adults aged 19 years and over using population-weighted, $1 \mathrm{~d}$ intake data from the Australian National Nutrition and Physical Activity Survey, May 2011-June 2012

\begin{tabular}{|c|c|c|c|c|c|c|c|c|c|}
\hline \multirow[b]{3}{*}{ Type of alcoholic beverage } & \multirow[b]{3}{*}{ Sex } & & & \multicolumn{6}{|c|}{ Consumers only } \\
\hline & & \multicolumn{2}{|c|}{$\begin{array}{l}\text { Population } \\
\text { prevalence }\end{array}$} & \multicolumn{3}{|c|}{$\begin{array}{l}\text { Alcoholic beverage intake } \\
\text { (standard drinks)* }^{\star}\end{array}$} & \multicolumn{3}{|c|}{$\begin{array}{c}\text { Percentage of total energy } \\
\text { from alcoholic beverages }(\%) \dagger\end{array}$} \\
\hline & & $\%$ & $95 \% \mathrm{Cl}$ & Median & 10th-90th percentile & $P \ddagger$ & Median & 10th-90th percentile & $P \ddagger$ \\
\hline \multirow[t]{2}{*}{ Beer } & Men & $19 \cdot 4$ & $18 \cdot 2,20 \cdot 5$ & 3.06 & $1.29-9.05$ & & $12 \cdot 2$ & $4 \cdot 2-32 \cdot 8$ & \\
\hline & Women & 2.9 & $2 \cdot 4,3.4$ & 1.40 & $1 \cdot 04-5 \cdot 18$ & $<0.001$ & $8 \cdot 2$ & $3.5-21.9$ & $<0.001$ \\
\hline \multirow[t]{2}{*}{ Red Wine } & Men & $8 \cdot 7$ & $7 \cdot 9,9.5$ & $3 \cdot 81$ & $1 \cdot 63-8 \cdot 17$ & & $10 \cdot 7$ & $4 \cdot 2-25 \cdot 7$ & \\
\hline & Women & $7 \cdot 8$ & $7 \cdot 0,8 \cdot 6$ & $3 \cdot 18$ & $0.76-8.01$ & $<0.001$ & $11 \cdot 7$ & $3 \cdot 0-28 \cdot \cdot 2$ & 0.38 \\
\hline \multirow[t]{2}{*}{ White Wine } & Men & $5 \cdot 1$ & $4 \cdot 5,5 \cdot 8$ & $2 \cdot 94$ & $1.46-11.51$ & & $10 \cdot 1$ & $4 \cdot 2-28 \cdot 6$ & \\
\hline & Women & $10 \cdot 1$ & $9 \cdot 2,11.0$ & $3 \cdot 26$ & $1 \cdot 37-8 \cdot 82$ & 0.76 & $12 \cdot 8$ & $5 \cdot 2-33 \cdot 9$ & 0.001 \\
\hline \multirow[t]{2}{*}{ Low-Alcohol Wine or Beer } & Men & $6 \cdot 2$ & $5 \cdot 6,6 \cdot 9$ & 1.91 & $0.82-6.14$ & & $9 \cdot 1$ & $3 \cdot 8-24 \cdot 8$ & \\
\hline & Women & 1.0 & $0 \cdot 7,1 \cdot 2$ & $1 \cdot 25$ & $0.77-6 \cdot 14$ & 0.001 & $5 \cdot 7$ & $3 \cdot 1-33 \cdot 4$ & 0.004 \\
\hline \multirow[t]{2}{*}{ Spirits } & Men & $4 \cdot 0$ & $3 \cdot 5,4 \cdot 6$ & $2 \cdot 36$ & $0.89-8.86$ & & $8 \cdot 0$ & $2 \cdot 1-26 \cdot 9$ & \\
\hline & Women & $2 \cdot 2$ & $1 \cdot 8,2 \cdot 6$ & $2 \cdot 36$ & $0.88-9.17$ & 0.94 & $9 \cdot 7$ & $2 \cdot 3-31 \cdot 0$ & 0.04 \\
\hline \multirow[t]{2}{*}{ Premixes } & Men & 2.5 & $2 \cdot 1,3 \cdot 0$ & $2 \cdot 29$ & $1 \cdot 10-5 \cdot 72$ & & $16 \cdot 7$ & $7 \cdot 0-39 \cdot 2$ & \\
\hline & Women & $1 \cdot 2$ & $0.9,1.5$ & 1.92 & $0.92-10.0$ & 0.85 & $18 \cdot 3$ & $7 \cdot 7-71 \cdot 9$ & 0.14 \\
\hline \multirow[t]{2}{*}{ Mixed Drinks or Cocktails } & Men & $1 \cdot 1$ & $0.8,1.4$ & 2.46 & $1 \cdot 12-6 \cdot 34$ & & $14 \cdot 8$ & $3 \cdot 1-25 \cdot 4$ & \\
\hline & Women & 1.4 & $1 \cdot 1,1 \cdot 7$ & 1.59 & $0.55-4.01$ & 0.002 & 9.5 & $2 \cdot 6-21 \cdot 6$ & 0.09 \\
\hline \multirow[t]{2}{*}{ Fortified Wine } & Men & 0.6 & $0.4,0.9$ & $2 \cdot 12$ & $0.70-6.36$ & & 9.4 & $2 \cdot 0-30 \cdot 6$ & \\
\hline & Women & 0.5 & $0.3,0.7$ & $1 \cdot 16$ & $0.42-4.67$ & 0.20 & $7 \cdot 6$ & $2 \cdot 8-23 \cdot 7$ & 0.69 \\
\hline \multirow[t]{2}{*}{ Cider } & Men & 0.9 & $0 \cdot 6,1 \cdot 1$ & 2.53 & $1 \cdot 25-5 \cdot 61$ & & $10 \cdot 2$ & $4 \cdot 5-21 \cdot 7$ & \\
\hline & Women & 0.5 & $0.3,0.7$ & 1.44 & $0.61-6.78$ & 0.18 & 8.0 & $3 \cdot 8-26 \cdot 2$ & 0.67 \\
\hline \multirow[t]{2}{*}{ Liqueurs } & Men & 0.4 & $0.3,0.6$ & $1 \cdot 38$ & $0.43-5.04$ & & 11.5 & $2.0-21.9$ & \\
\hline & Women & 0.4 & $0.2,0.6$ & 0.80 & $0.49-14.0$ & 0.73 & $5 \cdot 6$ & $1 \cdot 7-39 \cdot 2$ & 0.80 \\
\hline
\end{tabular}

*One standard drink contains $10 \mathrm{~g}$ of alcohol ${ }^{(27)}$.

†Percentage of total energy from alcoholic beverages includes energy from soft drinks mixed with alcoholic beverages where applicable.

¥The Mann-Whitney $U$ test was used to test for differences in alcoholic beverage intake and percentage energy from alcoholic beverages between men and women for different types of alcoholic beverage. 


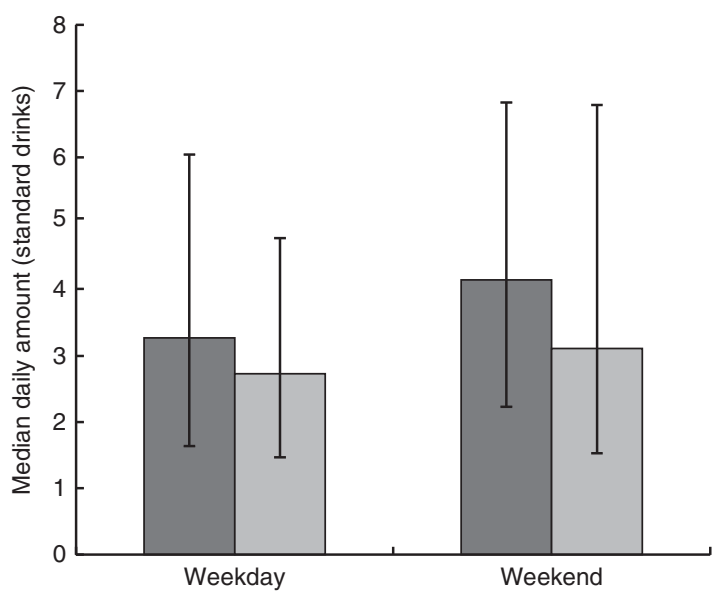

Fig. 1 Daily consumption of alcoholic beverages among Australian adult consumers by weekday or weekend. Values are medians, with 25th to 75th percentile represented by vertical bars, for adults ( $\square$, men; $\square$, women) aged 19 years and over using population-weighted, $1 \mathrm{~d}$ intake data from the Australian National Nutrition and Physical Activity Survey, May 2011-June 2012. Weekend is defined as Friday, Saturday and Sunday; one standard drink contains $10 \mathrm{~g}$ of alcohol ${ }^{(27)}$ Distribution of intake is significantly different between weekday and weekend for men $(P<0.001)$ and for women $(P=0.001)$

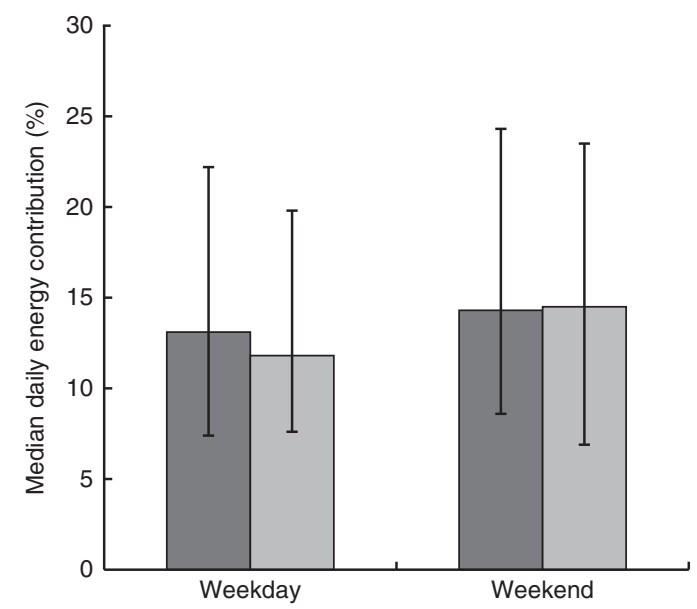

Fig. 2 Daily contribution of alcoholic beverages to total energy intake among Australian adult consumers by weekday or weekend. Values are medians, with 25th to 75th percentile represented by vertical bars, for adults ( $\square$, men; $\square$, women) aged 19 years and over using population-weighted, $1 \mathrm{~d}$ intake data from the Australian National Nutrition and Physical Activity Survey, May 2011-June 2012. Weekend is defined as Friday, Saturday and Sunday; percentage of total energy from alcoholic beverages includes energy from soft drinks mixed with alcoholic beverages where applicable. Distribution of energy contribution is significantly different between weekday and weekend for men $(P<0.001)$ and for women $(P=0.02)$. Median is not significantly different between men and women for weekdays $(P=0.09)$ or for weekend days $(P=0.50)$

household income $(P<0.05$; Table 5$)$. The prevalence of consumption of alcoholic beverages increased monotonically with household income quintile (Table 5).

\section{Association with adiposity categories}

A significantly higher percentage of people in the overweight category consumed an alcoholic beverage on the day preceding the survey, compared with people in the underweight, healthy weight or obese categories (Table 6). Similarly, a higher percentage of people in the increased risk category for waist circumference consumed an alcoholic beverage compared with people in the no risk or high risk categories.

People in the high risk category for waist circumference (i.e. the largest waist circumference) who consumed alcoholic drinks consumed significantly more standard drinks than people in other waist circumference categories and had a higher percentage contribution from alcoholic drinks to their total dietary energy intake. There was no significant difference across BMI categories for amount of alcoholic beverages consumed among those who consumed them, although the percentage contribution to total energy intake from alcoholic drinks was higher for people in the obese category compared with people in the healthy weight category (Table 6).

\section{Discussion}

For Australian adults aged 19 years and over in 2011-2012 who consumed alcoholic drinks on the day preceding the survey - a quarter of adult women and $40 \%$ of adult men - the contribution of the drinks to energy intake was substantial with a median value of $13 \%$ of total energy intake. Furthermore, $82 \%$ of Australian adults had reported consuming alcohol in the past year ${ }^{(2)}$. Alcoholic beverages are therefore a notable component in the dietary intake of Australian adults for their contribution to energy intake alone. The consumption of alcoholic beverages is discretionary and can be forgone without negative impact on dietary quality.

The prevalence of alcoholic beverage consumption by adults and the intake by consumers were higher on weekend days compared with weekdays. The definition of 'weekend' is important. The current analysis shows that alcoholic beverage intake on Friday is more consistent with intake on Saturday and Sunday than with intake on other days of the week, implying that Friday should be included in the definition of weekend with respect to intake of alcoholic beverages. To reduce population contribution of alcoholic beverages to energy intake, strategies that reduce the number of drinking days should be considered in addition to strategies to reduce the intake on a day when alcoholic beverages are consumed.

Similar results have been reported in other developed countries. The National Diet and Nutrition Survey (NDNS) of British adults aged 19-64 years in 2000-2001 ${ }^{(18)}$, as well as the National Health and Nutrition Examination Survey (NHANES) of US adults aged 20 years and over from 2003-2008 ${ }^{(17)}$ both showed a pattern of increased total alcoholic beverage consumption on weekend days 
Table 5 Percentage who consumed an alcoholic beverage, their median intake and median percentage of total energy contribution, by equivalised household income quintile, for adults aged 19 years and over using population-weighted, $1 \mathrm{~d}$ intake data from the Australian National Nutrition and Physical Activity Survey, May 2011-June 2012

\begin{tabular}{|c|c|c|c|c|c|c|}
\hline \multirow[b]{3}{*}{ Equivalised income quintile } & \multirow{2}{*}{\multicolumn{2}{|c|}{ Population prevalence }} & \multicolumn{4}{|c|}{ Consumers only } \\
\hline & & & \multicolumn{2}{|c|}{$\begin{array}{l}\text { Alcoholic beverage intake } \\
\text { (standard drinks)* }{ }^{*},\end{array}$} & \multicolumn{2}{|c|}{$\begin{array}{l}\text { Percentage of total energy from } \\
\text { alcoholic beverages }(\%)^{\star}, \ddagger\end{array}$} \\
\hline & $\%$ & $95 \% \mathrm{Cl}$ & Median & 10th-90th percentile & Median & 10th-90th percentile \\
\hline 1 & $24 \cdot 3$ & $22 \cdot 2,26 \cdot 5$ & $3.05^{a}$ & $0.99-10 \cdot 12$ & $14 \cdot 2^{\mathrm{a}, \mathrm{b}}$ & $4 \cdot 8-35 \cdot 3$ \\
\hline 2 & $26 \cdot 3$ & $24 \cdot 0,28 \cdot 6$ & $3.40^{\mathrm{a}, \mathrm{b}}$ & $1.30-10.03$ & $15 \cdot 0^{\mathrm{a}}$ & $5 \cdot 6-37 \cdot 8$ \\
\hline 3 & $32 \cdot 7$ & $30 \cdot 4,34.9$ & $3.43^{a, b}$ & $1.22-9.09$ & $14 \cdot 1^{\mathrm{a}}$ & $4.6-33.5$ \\
\hline 4 & $37 \cdot 8$ & $35 \cdot 6,40 \cdot 0$ & $3 \cdot 27^{a}$ & $1.06-8.58$ & $12 \cdot 2^{b}$ & $4 \cdot 2-30 \cdot 3$ \\
\hline 5 & $42 \cdot 7$ & $40 \cdot 4,45 \cdot 0$ & $3.84^{\mathrm{b}}$ & $1 \cdot 36-12 \cdot 23$ & $13 \cdot 9^{a}$ & $4 \cdot 8-38.9$ \\
\hline
\end{tabular}

Data were provided by 8425 participants.

${ }^{\mathrm{a}, \mathrm{b}}$ Median values in the same column with unlike superscript letters were significantly different $(P<0.05)$.

*The independent-samples Kruskal-Wallis test, followed by pairwise comparisons, was used to test for differences in alcoholic beverage intake and percentage energy from alcoholic beverages between quintiles.

†One standard drink contains $10 \mathrm{~g}$ of alcohol $^{(27)}$.

†Percentage of total energy from alcoholic beverages includes energy from soft drinks mixed with alcoholic beverages where applicable.

Table 6 Percentage who consumed an alcoholic beverage, their median intake and median percentage of total energy contribution, by adiposity category, for adults aged 19 years and over using population-weighted, $1 \mathrm{~d}$ intake data from the Australian National Nutrition and Physical Activity Survey, May 2011-June 2012

\begin{tabular}{|c|c|c|c|c|c|c|}
\hline \multirow[b]{3}{*}{ Adiposity category* } & \multirow{2}{*}{\multicolumn{2}{|c|}{$\begin{array}{l}\text { Population } \\
\text { prevalence }\end{array}$}} & \multicolumn{4}{|c|}{ Consumers only } \\
\hline & & & \multicolumn{2}{|c|}{$\begin{array}{l}\text { Alcoholic beverage intake } \\
\text { (standard drinks) } \dagger, \ddagger\end{array}$} & \multicolumn{2}{|c|}{$\begin{array}{l}\text { Percentage of total energy from } \\
\text { alcoholic beverages }(\%) \dagger, \S\end{array}$} \\
\hline & $\%$ & $95 \% \mathrm{Cl}$ & Median & 10th-90th percentile & Median & 10th-90th percentile \\
\hline \multicolumn{7}{|l|}{ BMl category } \\
\hline Underweight & $18 \cdot 4$ & $12 \cdot 0,24 \cdot 8$ & 2.50 & $1 \cdot 27-13 \cdot 71$ & $12 \cdot 2^{\mathrm{a}, \mathrm{b}}$ & $2 \cdot 6-46.5$ \\
\hline Healthy weight & 29.7 & $28 \cdot 1,31 \cdot 4$ & $3 \cdot 27$ & $1 \cdot 10-8 \cdot 87$ & $12 \cdot 2^{\mathrm{a}}$ & $4 \cdot 7-35 \cdot 8$ \\
\hline Overweight & $40 \cdot 3$ & $38 \cdot 5,42 \cdot 0$ & 3.43 & $1.11-10 \cdot 33$ & $13 \cdot 6^{a, b}$ & $4 \cdot 4-35 \cdot 6$ \\
\hline Obese & $31 \cdot 0$ & $29 \cdot 0,33 \cdot 0$ & 3.54 & $1 \cdot 17-10 \cdot 37$ & $14 \cdot 9^{b}$ & $5 \cdot 6-36 \cdot 2$ \\
\hline \multicolumn{7}{|c|}{ Waist circumference category } \\
\hline Not at risk & 31.0 & $29 \cdot 3,32 \cdot 6$ & $3.24^{\mathrm{a}}$ & $1.02-9.35$ & $12 \cdot 2^{\mathrm{a}}$ & $4 \cdot 2-33 \cdot 4$ \\
\hline Increased risk & 38.9 & $36 \cdot 6,41 \cdot 1$ & $3 \cdot 21^{a}$ & $1.06-8.87$ & $12 \cdot 6^{\mathrm{a}}$ & $4 \cdot 6-33 \cdot 1$ \\
\hline High risk & 33.8 & $32 \cdot 2,35 \cdot 5$ & $4.09^{b}$ & $1 \cdot 26-11 \cdot 64$ & $15 \cdot 8^{b}$ & $5 \cdot 4-38 \cdot 1$ \\
\hline
\end{tabular}

${ }^{a, b}$ For each adiposity variable, median values within a column with unlike superscript letters were significantly different $(P<0.05)$.

${ }^{*}$ BMl was measured for 7873 participants. BMl categories are: underweight, $<18.50 \mathrm{~kg} / \mathrm{m}^{2}$; healthy weight, 18.50 to $24.99 \mathrm{~kg} / \mathrm{m}^{2}$; overweight, 25.00 to $29.99 \mathrm{~kg} / \mathrm{m}^{2}$; obese, $\geq 30.00 \mathrm{~kg} / \mathrm{m}^{2}$. Waist circumference was measured for 7850 participants. Increased risk category is $>80 \mathrm{~cm}$ for women and $>94 \mathrm{~cm}$ for men; high risk category is $>88 \mathrm{~cm}$ for women and $>102 \mathrm{~cm}$ for men.

†The independent-samples Kruskal-Wallis test, followed by pairwise comparisons, was used to test for differences in prevalence, alcoholic beverage intake and percentage energy from alcoholic beverages between adiposity categories.

¥One standard drink contains $10 \mathrm{~g}$ of alcohol ${ }^{(27)}$.

$\S$ Percentage of total energy from alcoholic beverages includes energy from soft drinks mixed with alcoholic beverages where applicable.

compared with weekdays. Data from the European Prospective Investigation into Cancer and Nutrition (EPIC) cohort showed a marked increase in alcoholic beverage consumption on weekends compared with weekdays for men in Sweden and the north of Spain (Asturias, Navarra and San Sebastian) and for women in Greece, Spain, France, Germany, the Netherlands, UK, Denmark, Sweden and Norway, although little variation between weekdays and weekends was seen for men in Germany, Granada in Spain, and for both men and women in Italy ${ }^{(19)}$. In the 1995 Australian National Nutrition Survey, men and women had a similar prevalence of alcohol consumption to the more recent results ( 42 and $24 \%$ in $1995 v .40$ and $25 \%$ in 2011-2012 in men and women, respectively) ${ }^{(16)}$.
The percentage contribution from alcoholic beverages to total energy was higher in adult men (10\%) than women (3\%) in $1995^{(16)}$; however, the definition of alcoholic beverages did not include soft drinks and fruit juices mixed with alcoholic beverages. Despite the difference in definitions, the percentages of adults consuming mixed drinks, spirits and liqueurs are relatively small, and the mean daily amount of pure alcohol consumed by adults was $12 \cdot 8 \mathrm{~g}$ in $1995^{(16)}$ and $14.4 \mathrm{~g}$ in $2011-2012^{(22)}$. This is inconsistent with a report concluding that the per capita intake of alcohol has been declining for the 6 years prior to $2013 / 2014$ and at the end of the period was at the lowest level since 1962/1963(29). However, that report was based on apparent consumption of alcohol (alcoholic 
beverages sold) and the method does not adjust for wastage or alcohol used in cooking.

The consumption of a larger average or median daily amount of alcohol by men compared with women is a common and consistent finding in developed countries $^{(17-19,30)}$ and is likely to be related to the body size differences between men and women. Compared with men, women generally have a smaller volume of body water in which alcohol is distributed, as well as lower gastric alcohol dehydrogenase activity, and therefore women reach higher peak blood alcohol levels than men from equivalent doses of alcohol ${ }^{(30,31)}$. Higher blood alcohol levels per unit of alcohol consumed for women could influence them to drink less than men as the potential effect of alcohol would start with a lower quantity consumed ${ }^{(30)}$. The smaller body size and energy requirement of women account for the similarity of contribution of alcoholic beverages to energy intake between women and men, despite the difference in absolute amount consumed.

The youngest age group (19-24 years) had the lowest prevalence of alcoholic drink consumption for both men and women. This should not be understood to mean that alcohol drinking is less of a problem in this age group. In the same survey, a short question was asked whether the participant had consumed more than 4 standard drinks (the single occasion risk threshold) in the past year. While $57.8 \%$ of Australian men and $31.9 \%$ of Australian women reported consuming more than 4 standard drinks at least once in the past year, for the youngest age group (18-24 years) it was $74.4 \%$ of men and $59.1 \%$ of women - the highest percentage of any age group ${ }^{(2)}$. Drinking less often, but in high amounts (i.e. binge drinking), is similar to the consumption pattern found in younger drinkers (aged 12-20 years) by the National Institute of Alcohol Abuse and Alcoholism in the USA ${ }^{(32)}$. Binge drinking may be more prominent among this age group due to social activities associated with drinking.

\section{Type of alcobol}

Beer was the most commonly consumed alcoholic beverage for Australian men and was predominantly responsible for the higher intake of total alcoholic beverages on weekend days for men. Australian women showed an increase in prevalence of consumption, and in mean intake, across a number of alcoholic beverages on the weekend, although to a much lesser extent than for men.

Studies in other Western countries have also reported beer to be the most commonly consumed alcoholic beverage among men and wine among women (including the $\mathrm{UK}^{(19,33)}$, the USA ${ }^{(17,34)}$, Germany ${ }^{(19)}$, the Netherlands ${ }^{(19)}$ and Sweden $\left.{ }^{(19)}\right)$. In contrast, wine was the most prevalent alcoholic beverage consumed among men in Italy and Greece $^{(19)}$. In Spain, beer has been found to be the preferred alcoholic beverage for men and (by a small margin) for women, although men and women in the older age groups prefer wine ${ }^{(35)}$.
Globally, $50 \cdot 1 \%$ of the total recorded alcohol intake is consumed in the form of spirits, followed by beer (34.8\%), with wine accounting for only $8.0 \%$ of total recorded alcohol consumption ${ }^{(4)}$. The high consumption of spirits is influenced by large populations in the SouthEast Asia and Western Pacific regions who consume spirits $^{(4)}$.

\section{Association with bousebold income}

Those in the top quintile of equivalised household income showed the highest prevalence of alcoholic beverage consumption, close to double the prevalence of intake in the lowest income quintile. The amount consumed among consumers measured in standard drinks was also significantly higher in the top quintile compared with the lowest quintile, although the difference in median intake was less than 0.8 of a standard drink. Results from other developed countries are consistent. In a Dutch study using national data, there was a greater percentage of chronic heavy drinkers at higher equivalised income and also a greater percentage of episodic heavy drinkers ${ }^{(36)}$. A Welsh study ${ }^{(37)}$ showed similar results when socio-economic status was measured using employment category. An analysis of New Zealand data which estimated intake on a typical occasion indicated that while higher-income groups drank alcoholic drinks more frequently, they drank a smaller quantity on a typical drinking occasion ${ }^{(38)}$.

\section{Association with measures of adiposity}

An analysis of US NHANES survey data found that the prevalence of overweight or obesity was significantly higher among heavy drinkers (four or more drinks in a day), than among those who consumed the same amount of alcohol over multiple sessions ${ }^{(39)}$. Similarly, findings from the British Regional Heart Study, a prospective cohort study of British men, reported that heavy drinkers (defined as 8 units of alcohol in a day) aged 40-59 years had the highest prevalence of weight gain and obesity when followed up 5 years later ${ }^{(40)}$. Furthermore, a cross-sectional study of men and women in Denmark found that obesity was inversely associated with drinking frequency, whereas the amount of alcohol consumed at any one time was positively associated with obesity ${ }^{(41)}$. While heavy or binge drinking has been found to be associated with obesity, studies have also reported that light or moderate alcohol consumption is not ${ }^{(39,42)}$. The present study could not categorise participants according to their drinking habit, but obese participants did not show a higher prevalence of consumption of alcoholic beverages on the day preceding the survey than participants of healthy weight. When alcoholic drinks were consumed, obese participants consumed a significantly greater percentage of their total energy from alcoholic beverages than healthy weight participants. This is not reflected in the reported intake of standard drinks, for which there was no statistically 
significant difference between groups, perhaps because of differential under-reporting of food intake (but not alcoholic beverage intake) by obesity status.

Those in the largest waist circumference category who drank alcoholic beverages on the day preceding the survey had significantly more standard drinks than those in the other categories and a greater contribution to energy intake from alcoholic beverages. Beer consumption was associated with waist circumference gain in men but not women in the EPIC study ${ }^{(43)}$. It has been suggested that this difference between sexes may be a consequence of habitual drink choice, with men consuming more beer. The additional energy derived from beer for the same quantity of alcohol, compared with wine, may enhance the risk of weight gain in men more than women ${ }^{(44)}$. A systematic review on beer consumption and abdominal obesity found that beer intake of greater than $500 \mathrm{ml} / \mathrm{d}$ was positively associated with abdominal obesity ${ }^{(45)}$.

In the $\mathrm{EU}$, there has been a recent call to include the energy content on the label of alcoholic drinks in response to the high prevalence of obesity ${ }^{(46)}$. Currently, as in Australia, the requirements include labelling of the alcohol content by volume on alcoholic drinks; however, alcohol is only one component of the total energy content.

\section{Strengths and limitations}

The strengths of the present study include the use of a large nationally representative sample of Australian adults from a survey with a high response proportion (77\%). Data on alcohol intake were collected using a detailed and standardised recall method. Using these data, beverages that were mixed with alcoholic beverages could be included; this gives a more comprehensive insight into the energy implications of consumption of alcoholic drinks by Australian adults compared with focusing on the alcohol content of drinks alone.

Cross-sectional data can describe associations between alcoholic beverage intake and other factors, not attribute causation. Furthermore, the measurement of dietary intake is problematical. A single $24 \mathrm{~h}$ dietary recall cannot distinguish between regular drinkers, occasional drinkers and non-drinkers. For this reason, these analyses rely on comparisons of intake between groups categorised on stable characteristics rather than intake based on shortterm measurement. Under-reporting of intake is well recognised for dietary intake in general ${ }^{(47)}$ and alcohol use in particular ${ }^{(48,49)}$. Under-reporting in the present survey was found to be progressively higher for overweight and for obese people $\mathrm{e}^{(23)}$.

The dietary recall measurement for Saturday was conducted on relatively few adult survey participants (about one-third of the number for Friday, which had the next fewest participants). This reduces the statistical power of comparisons with this day. The day of the dietary measurement interview was chosen by the participant, which raises a question of response bias in relation to dietary intake such as alcoholic beverages.

Individuals who consumed large amounts of alcoholic beverages on the night prior to the dietary measurement interview might be less likely to present for interview and perhaps less accurate in their recall of dietary intake. The 90th percentile of daily alcoholic beverage intake on a single day for both 19-24-year-olds and 25-44-year-olds is high at over 10 standard drinks - an intake that might be expected to have residual effects on the following day, not the least being potentially an effect on memory.

\section{Conclusion}

Alcoholic drinks contribute substantially to the dietary energy intake of Australian adults. Consumption of alcoholic beverages in Australia is higher on weekends (including Fridays) than on weekdays, with 19-64-year-old male consumers and consumers in the highest weight circumference category having the highest intakes. A higher proportion of people in the highest income category are likely to consume alcoholic beverages on any particular day and to consume more than people in the lowest income category. Beer and white wine are the most commonly consumed drinks among men and women, respectively.

The need to moderate alcoholic beverage consumption in the Australian population is apparent. Strategies to reduce consumption could be targeted at men and people with a higher income, with a focus on reducing either the amount of alcoholic beverage consumed on each consumption occasion or the number of days per week that alcohol is consumed, or both. Weekends, starting on Friday, are when a larger percentage of Australian adults drink alcoholic beverages. Future research to understand patterns of alcohol consumption at the individual level will help assess its specific contribution to weight gain. Obtaining information about the context in which alcoholic beverages are consumed may assist in directing future strategies to lower its consumption.

\section{Acknowledgements}

Acknowledgements: The authors thank Julie Syrette, Gilly Hendrie and Danielle Baird of the CSIRO for their advice and support in the production of this manuscript. Financial support: This research received no specific grant from any funding agency in the public, commercial or notfor-profit sectors. Conflict of interest: None. Authorship: B.S.W. and M.D.R. formulated the research questions. B.S.W. and M.D.R. assisted with data preparation. M.D.R. and B.S.W. carried out statistical analyses. B.S.W., K.M.D. and M.D.R. were involved in the data interpretation. B.S.W. wrote the manuscript and all authors critically reviewed and approved the final manuscript. Ethics of buman subject participation: The NNPAS was conducted 
by the Australian Bureau of Statistics under the Census and Statistics Act 1905 (amended) of the Australian Government which guarantees confidentiality for the individual of the gathered information.

\section{References}

1. VicHealth (2013) Drinking-related lifestyles: exploring the role of alcohol in Victorians' lives. Research summary. http://www.vichealth.vic.gov.au/drinking-lifestyles (accessed October 2014)

2. Australian Bureau of Statistics (2012) Australian Health Survey: First Results, 2011-12. http://www.abs.gov.au/ ausstats/abs@.nsf/0/D522399EBE2DAB46CA257AA30014BE96? opendocument (accessed December 2015).

3. National Health and Medical Research Council (2011) Alcohol guidelines: reducing the health risks. https://www. nhmrc.gov.au/your-health/alcohol-guidelines (accessed October 2014)

4. World Health Organization (2014) Global status report on alcohol and health 2014. http://apps.who.int/iris/bitstream/ 10665/112736/1/9789240692763_eng.pdf?ua=1 （accessed December 2014).

5. Bowden JA, Delfabbro P, Room R et al. (2014) Alcohol consumption and NHMRC guidelines: has the message got out, are people conforming and are they aware that alcohol causes cancer? Aust N Z J Public Health 38, 66-72.

6. Ronksley PE, Brien SE, Turner BJ et al. (2011) Association of alcohol consumption with selected cardiovascular disease outcomes: a systematic review and meta-analysis. BMJ 342, d671.

7. Roerecke M \& Rehm J (2010) Irregular heavy drinking occasions and risk of ischemic heart disease: a systematic review and meta-analysis. Am J Epidemiol 171, 633-644.

8. Yeomans MR, Hails NJ \& Nesic JS (1999) Alcohol and the appetizer effect. Behav Pharmacol 10, 151-161.

9. Westerterp-Plantenga MS \& Verwegen CRT (1999) The appetizing effect of an aperitif in overweight and normalweight humans. Am J Clin Nutr 69, 205-212.

10. Sayon-Orea C, Martinez-Gonzalez MA \& Bes-Rastrollo M (2011) Alcohol consumption and body weight: a systematic review. Nutr Rev 69, 419-431.

11. Fischer S \& Smith GT (2008) Binge eating, problem drinking, and pathological gambling: linking behavior to shared traits and social learning. Pers Individ Diff 44, 789-800.

12. World Health Organization (2014) Obesity and overweight. http://www.who.int/mediacentre/factsheets/ fs311/en/ (accessed October 2014).

13. Australian Bureau of Statistics (2014) Overweight and obesity. http://www.abs.gov.au/ausstats/abs@.nsf/Lookup/ by\%20Subject/4338.0 2011-13 Main\%20Features Overweight $\% 20$ and $\% 20$ obesity 10007 (accessed November 2014)

14. Australian Institute of Health and Welfare (2014) Overweight and obesity. http://www.aihw.gov.au/over weight-and-obesity/ (accessed November 2014).

15. Racette SB, Weiss EP, Schechtman KB et al. (2008) Influence of weekend lifestyle patterns on body weight. Obesity (Silver Spring) 16, 1826-1830.

16. Australian Bureau of Statistics (1995) National Nutrition Survey, Foods Eaten, Australia, 1995. http://www.ausstats. abs.gov.au/ausstats/subscriber.nsf/0/CA25687100069892CA 256888001CD460/\$File/48040_1995.pdf (accessed December 2014).

17. Breslow RA, Chen CM, Graubard BI et al. (2013) Diets of drinkers on drinking and nondrinking days: NHANES 2003-2008. Am J Clin Nutr 97, 1068-1075.
18. Gibson S \& Shirreffs SM (2013) Beverage consumption habits '24/7' among British adults: association with total water intake and energy intake. Nutr $J \mathbf{1 2}, 9$

19. Sieri S, Agudo A, Kesse E et al. (2002) Patterns of alcohol consumption in 10 European countries participating in the European Prospective Investigation into Cancer and Nutrition (EPIC) project. Public Health Nutr 5, 1287-1296.

20. Studer J, Baggio S, Daeppen JB et al. (2014) Differential association of drinking motives with alcohol use on weekdays and weekends. Psychol Addict Behav 28, 651-658.

21. Australian Bureau of Statistics (2014) About the Australian Health Survey. http://www.abs.gov.au/ausstats/abs@. nsf/Lookup/4364.0.55.001Chapter1202011-12 (accessed December 2014).

22. Australian Bureau of Statistics (2014) Australian Health Survey: Nutrition First Results - Foods and Nutrients, 2011-12. National Nutrition and Physical Activity Survey (NNPAS).http://www.abs.gov.au/ausstats/abs@.nsf/mf/ 4364.0.55.007 (accessed December 2015).

23. Australian Bureau of Statistics (2014) Australian Health Survey: Users' Guide, 2011-13. http://www.abs.gov. au/ausstats/abs@.nsf/PrimaryMainFeatures/4363.0.55.001? OpenDocument (accessed December 2015).

24. Australian Government Department of Health (2010) Secondary supply. http://www.alcohol.gov.au/internet/ alcohol/publishing.nsf/Content/secondary (accessed December 2015).

25. National Health and Medical Research Council (2013) Eat for Health; Australian Dietary Guidelines. http://www. eatforhealth.gov.au/sites/default/files/files/the_guidelines/ n55_australian_dietary_guidelines.pdf (accessed November 2014).

26. Food Standards Australian and New Zealand (2013) AUSNUT 2011-12 food and dietary supplement classification system. http://www.foodstandards.gov.au/ science/monitoringnutrients/ausnut/ausnutdatafiles/Pages/ foodclassification.aspx (accessed November 2014).

27. Australian Government Department of Health (2010) Standard drinks guide. http://www.alcohol.gov.au/internet/ alcohol/publishing.nsf/Content/drinksguide-cnt (accessed December 2014).

28. World Health Organization (2014) BMI Classification. http://apps.who.int/bmi/index.jsp?introPage=intro_3.html (accessed November 2014).

29. Australian Bureau of Statistics (2014) Apparent Consumption of Alcohol, Australia 2013-14. http://www.abs.gov.au/ausstats/abs@.nsf/mf/4307.0.55.001 (accessed December 2015).

30. Wilsnack RW, Vogeltanz ND, Wilsnack SC et al. (2000) Gender differences in alcohol consumption and adverse drinking consequences: cross-cultural patterns. Addiction 95, 251-265.

31. Frezza MMD, di Padova CMD, Pozzato GMD et al. (1990) High blood alcohol levels in women. $N$ Engl J Med 322, 95-99.

32. National Institute on Alcohol Abuse and Alcoholism (2014) Underage Drinking. http://www.niaaa.nih.gov/alcoholhealth/special-populations-co-occurring-disorders/underagedrinking (accessed December 2014).

33. Lader D \& Steel M (2010) Drinking: Adults' Behaviour and Knowledge in 2009. Opinions Survey Report no. 42. London: Office for National Statistics.

34. US Department of Health and Human Services (2012) Calories consumed from alcoholic beverages by US adults, 2007-2010. http://www.cdc.gov/nchs/data/databriefs/ db110.pdf (accessed December 2014).

35. Galán I, González MJ \& Valencia-Martín JL (2014) Alcohol drinking patterns in Spain: a country in transition. Rev Esp Salud Publica 88, 529-540. 
36. Kuipers MAG, Jongeneel-Grimen $\mathrm{B}$, Droomers $\mathrm{M}$ et al. (2013) Why residents of Dutch deprived neighbourhoods are less likely to be heavy drinkers: the role of individual and contextual characteristics. J Epidemiol Community Health 67, 587-594.

37. Fone DL, Farewell DM, White J et al. (2013) Socioeconomic patterning of excess alcohol consumption and binge drinking: a cross-sectional study of multilevel associations with neighbourhood deprivation. BMJ Open 3, e002337.

38. Huckle T, You RQ \& Casswell S (2010) Socio-economic status predicts drinking patterns but not alcohol-related consequences independently. Addiction 105, 1192-1202.

39. Arif A \& Rohrer J (2005) Patterns of alcohol drinking and its association with obesity: data from the Third National Health and Nutrition Examination Survey, 1988-1994. BMC Public Health 5, 126.

40. Wannamethee S \& Shaper AG (2003) Alcohol, body weight, and weight gain in middle-aged men. Am J Clin Nutr 77, 1312-1317.

41. Tolstrup JS, Heitmann BL, Tjonneland AM et al. (2005) The relation between drinking pattern and body mass index and waist and hip circumference. Int J Obes Relat Metab Disord 29, 490-497.

42. Breslow RA \& Smothers BA (2005) Drinking patterns and body mass index in never smokers: National Health
Interview Survey, 1997-2001. Am J Epidemiol 161, 368-376.

43. Schutze M, Schulz M, Steffen A et al. (2009) Beer consumption and the 'beer belly': scientific basis or common belief. Eur J Clin Nutr 63, 1143-1149.

44. Yeomans MR (2010) Alcohol, appetite and energy balance: is alcohol intake a risk factor for obesity? Physiol Behav 100, $82-89$.

45. Bendsen NT, Christensen R, Bartels EM et al. (2013) Is beer consumption related to measures of abdominal and general obesity? A systematic review and meta-analysis. Nutr Rev 71, 67-87.

46. Sim F (2015) Alcoholic drinks contribute to obesity and should come with mandatory calorie counts. BMJ 350, h2047.

47. Macdiarmid J \& Blundell J (1998) Assessing dietary intake: who, what and why of under-reporting. Nutr Res Rev 11, 231-253.

48. Midanik LT (1988) Validity of self-reported alcohol use: a literature review and assessment. $B r J$ Addict $\mathbf{8 3}$, 1019-1029.

49. Kerr WC, Patterson D, Koenen MA et al. (2009) Large drinks are no mistake: glass size, not shape, affects alcoholic beverage drink pours. Drug Alcohol Rev 28, 360-365. 